\title{
Editorial
}

\section{Acta Neuropsychiatrica 4.0}

This editorial - and my new role as the Editor-inChief - begins with looking back on the previous versions of Acta Neuropsychiatrica, beginning in 1989. The Founding Editor, M.J.A.J.M. Hoes, and the editor of Acta Neuropsychiatrica 2.0, Michael Maes, are acknowledged for their contribution and initial development of the Journal. However, it is a great pleasure for me to especially acknowledge and thank for the substantial work done by my predecessor, Gin S. Malhi. Without the enthusiasm, spirit, and energy you devoted to Acta Neuropsychiatrica 3.0, we would not have achieved the position we have today. I am also very much indebted to your assistance and guidance during the transition phase, and it is a privilege to include you in the future editorial board.

With the new version, I am also grateful for all the support and advice offered to me by the many senior and dedicated scientists who have agreed to contribute to this journal as members of the new editorial board. The new editorial board members each bring in substantial knowledge within the neuropsychiatric field, ranging from basic science to clinical neuropsychiatry, and covering distinct areas such as preclinical experimental neuropsychiatry, neuropharmacology, genetics, neuroimaging, epidemiology, clinical trials and statistical expertise. The origin and geographical location of board members reflect the international readership of the journal.

As stated in the aims of Acta Neuropsychiatrica, we welcome reviews, original research articles, rapid communications, case reports and debate papers. The overall purpose of Acta Neuropsychiatrica is to provide our readers with the latest perspectives from current and emerging areas, across all disciplines and fields relevant to neuropsychiatry.

This issue begins with a comprehensive and important critical review of the treatment of bipolar depression, emphasising the importance of individualised treatment (1). In two papers, the mitochondrial respiratory chain activity is examined in an animal model of mania (2) and following chronic administration of antidepressants (3). The influence of brain-derived neurotrophic factor and apolipoprotein $\mathrm{E}$ genetic variants on hemispheric and lateral ventricular volume are also examined in healthy adults (4).

As a new editor, I welcome all of you in this new version of Acta Neuropsychiatrica, encouraging scientists and clinicians to submit their research to us. I would also welcome any suggestions that readers may have to further improve the journal.

\section{Gregers Wegener \\ Centre for Psychiatric Research, Aarhus University, Aarhus, Denmark}

\section{References}

1. Tundo A, Cavalieri P, Navari S, Marchetti F. Treating bipolar depression - antidepressants and alternatives: a critical review of the literature. Acta Neuropsychiatr 2011;23:94-105.

2. Freitas TP, Rezin GT, Fraga DB et al. Mitochondrial respiratory chain activity in an animal model of mania induced by ouabain. Acta Neuropsychiatr 2011;23:106-111.

3. Scaini G, MagGi DD, De-Nês BT et al. Activity of mitochondrial respiratory chain is increased by chronic administration of antidepressants. Acta Neuropsychiatr 2011;23: 112-118.

4. Sidiropoulos C, Jafari-Khouzani K, Soltanian-Zadeh $\mathrm{H}$ et al. Influence of brain-derived neurotrophic factor and apolipoprotein E genetic variants on hemispheric and lateral ventricular volume of young healthy adults. Acta Neuropsychiatr 2011;23:132-138. 